Special issue of the 2nd International Conference on Computational and Experimental Science and Engineering (ICCESEN 2015)

\title{
Experimental Data of Research Using Ground-Penetrating Radar "Zond-12c" and Interpretation of Georadarograms
}

\author{
K. Iskakov, S. Boranbayev, Z. Alimbayeva And B. Issin* \\ L.N. Gumilyov Eurasian National University, Department of Computer Engineering, Astana, Kazakhstan
}

\begin{abstract}
The paper presents engineering methods for the interpretation of georadarograms. For this purpose experimental research using ground-penetrating radar "Zond-12c" were carried out, in which artificial objects, placed in the training laboratory ground, were studied. The aim of the research is the geophysical investigation of the structure of lower layers and presence of artificial objects for obtaining of analogy georadarograms. The experiments allow developing of technology for the interpretation of real ground-penetrating radar data from unknown objects. Experiments also allow us to solve the inverse problem of determining the geoelectric properties of environments [S.I. Kabanihin, K.T. Iskakov, M.A. Bektemesov, M.A. Shishlenin, Algorithms and numerical methods for the solution of inverse and ill-posed problems, Astana 2011 (in Russian)]. Application of ground-penetrating radar in restoring of the structure of the underground environment can be reduced to the solution of ill-posed problems for hyperbolic and parabolic types of equations. Many researchers describe algorithms for this kind of problems. At present, methods of interpretation of georadarograms can be improved by new achievements of the inverse problems theory. The bottleneck of application of the ground-penetrating radar is the complexity of interpreted data, requiring at the present stage to attract highly qualified professionals. Forming of own methods of interpreting ground-penetrating radar data contributes to preservation of confidential geophysical information.
\end{abstract}

DOI: 10.12693/APhysPolA.130.322

PACS/topics: 73.43.Fj, 01.50.hv

\section{Introduction}

Effective solution of the problems from various economic sectors and, in particular, of environmental management, management of problems of urban services, ecology, geology, archeology and others depend on the completeness and accuracy of the information about the location and status of the respective natural and manmade objects.

This paper presents engineering techniques for the interpretation of georadarograms. For this purpose, experimental studies with ground-penetrating radar (GPR) "Zond-12c" were carried out, to interpret the georadarograms derived from man-made objects.

The developed program for processing and visualization of georadar information was designed. The result of GPR survey is a set of single tracks (signals), which are recorded by a receiving antenna at each position of GPR. Typically, this set of tracks is displayed by the variable density method, as an image called georadarogram $[1,2]$.

In this paper, the previously studied GPR methods [3] were considered, in which a research was conducted on the surface of the airfield runway, located on the territory of Almaty in Kazakhstan.

\section{Tasks and methods}

The object of research is the training laboratory ground with different artificial objects placed in it.

\footnotetext{
*corresponding author; e-mail: issinbakhtiyar@gmail.com
}

The subject of research are methods of interpretation of georadarograms obtained by sensing and diagnostic methods with GPR "Zond-12c".

The tasks of research:

- Geophysical survey of the structure of base layers to detect objects with GPR "Zond-12c";

- Determination of the depth of the objects;

- Windowed Fourier transformation of georadarogram;

- Interpretation of resulting georadarograms.

Our method of research is the profile diagnostic continuous inspection method with different antennas at frequencies of $300 \mathrm{MHz}$ and $500 \mathrm{MHz}$, using GPR "Zond$12 \mathrm{c} "$.

Training laboratory ground is located $76 \mathrm{~km}$ from Astana in the north-west of Kazakhstan. At the training laboratory ground the following man-made objects were placed: iron barrel, brass plate, plastic barrel with an aluminum cable, copper cable, iron plates and a dugout.

\section{Experimental studies in the research laboratory ground}

Object "brass plate", used in this study, had the length of $70 \mathrm{~cm}$, width of $60 \mathrm{~cm}$ and thickness of $2 \mathrm{~cm}$. Figure 1 shows the placement of the "brass plate" test object in the trench at the training laboratory ground. The trench with length of $200 \mathrm{~cm}$, width of $73 \mathrm{~cm}$ and depth of $1.3 \mathrm{~m}$ was filled with sand before the experiment. 


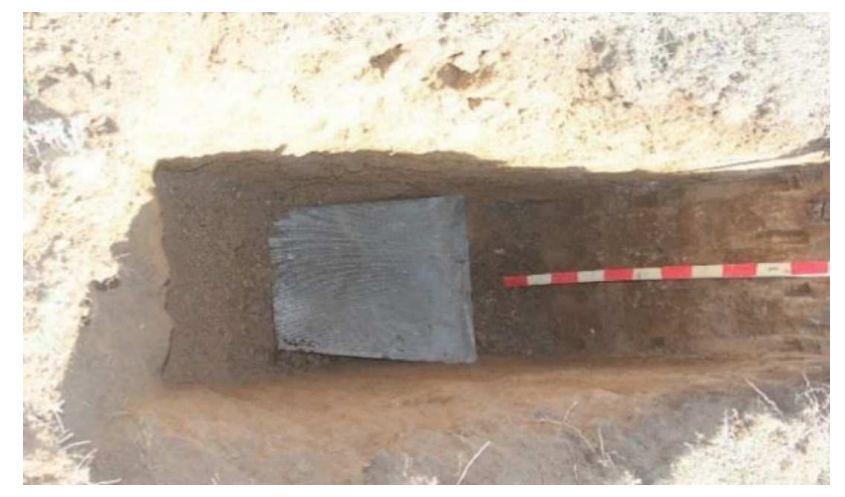

Fig. 1. The test object "brass plate" in the trench.

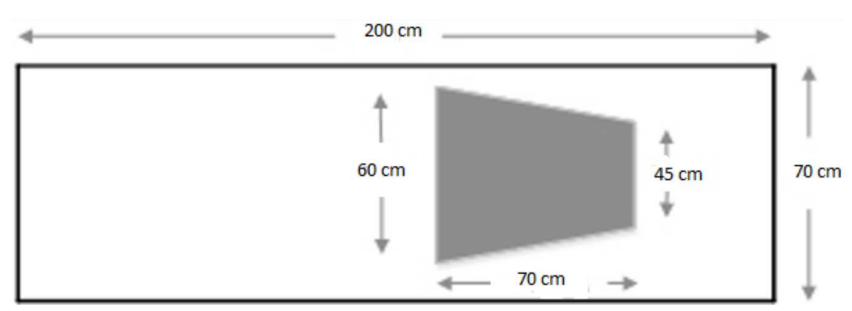

Fig. 2. Sketch of the "brass plate" test object.

Figure 2 shows a sketch of the "brass plate" test object. The result of the windowed Fourier transform of georadarogram of experimental sensing of the brass plate is presented in Fig. 3.

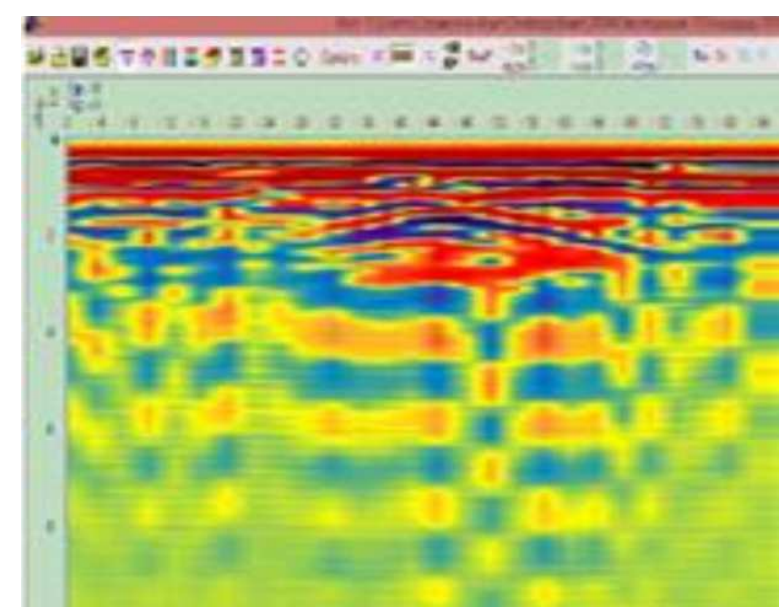

Fig. 3. Windowed Fourier transform of georadarogram of experimental sensing of the brass plate.

An example of a georadarogram track is shown in Fig. 4 and the Fourier spectrum of this track is shown in Fig. 5.

Windowed Fourier transformations using Hamming, Khan, Blackman and Chebyshev windows are shown in Fig. 6. Windows are used to reduce the side lobes of the spectrum. In this procedure the original signal $x(k)$ is multiplied by a temporary window function $w(k)$ and then the discrete Fourier transformation is performed.

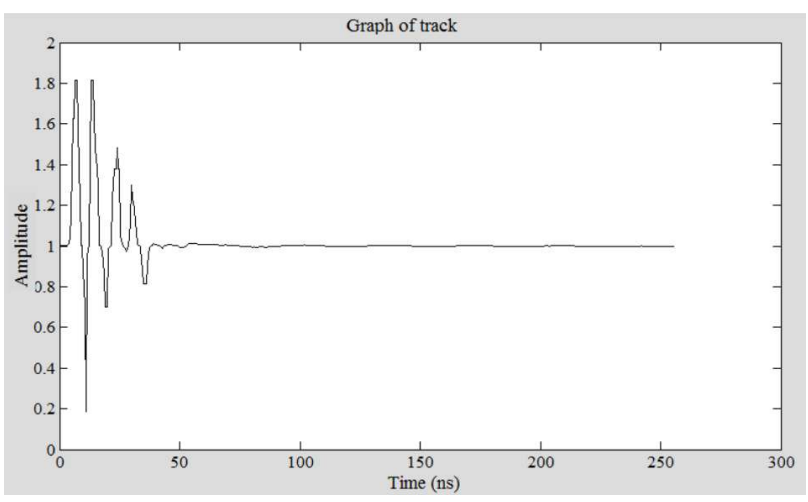

Fig. 4. An example of a georadarogram track.

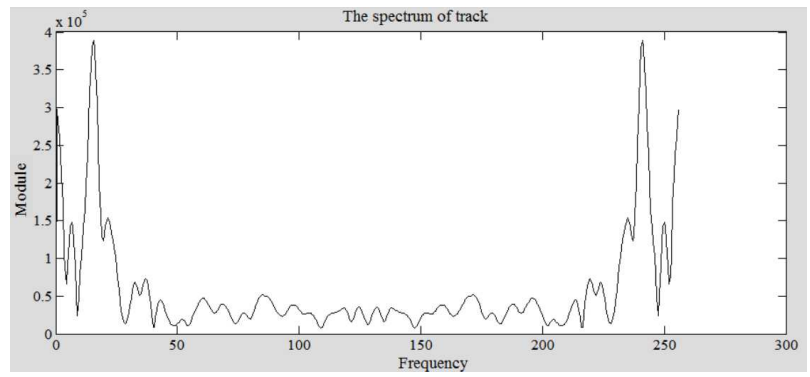

Fig. 5. The Fourier spectrum of the track from Fig. 4.

\section{Conclusions}

Our program for processing of georadarograms allows to test new algorithms of filtering and visualization. The program of visualization of georadarograms allows to view profile and graph of the georadarogram track. It also calculates the spectrum of the track using the algorithm of fast Fourier transformation with a variety of window functions.

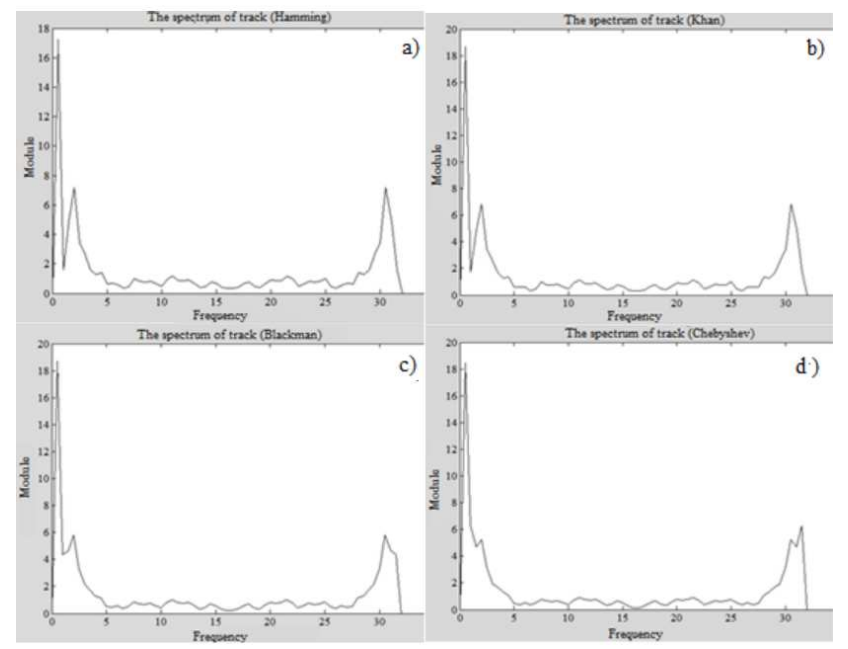

Fig. 6. Amplitude of the spectrum of georadarogram after windowed Fourier transformation using (a) Hamming, (b) Khan, (c) Blackman and (d) Chebyshev windows. 
The developed program can be used to decode and interpret the real GPR data, and for the development, testing and implementation of new methods and approaches for the processing of georadarograms.

\section{Acknowledgments}

The work was supported by a grant from the Ministry of Education and Science of the Republic of Kazakhstan (the contract No. 46 from 12.02.2015).

\section{References}

[1] M.L. Vladov, A.B. Starovoitov, Introduction to GPR, MGU, Moscow, 2004, p. 153 (in Russian).

[2] S.B. Izumov, S.B. Druchinin, A.S. Voznisenskii Theory and methods of GPR, Gornaya Kniga, Moscow 2008, p. 196 (in Russian).

[3] M. Zhartybayeva, Z. Oralbekova, K. Iskakov, Acta Phys. Pol. A 128, B-467 (2015). 